\title{
The canine counts! Significance of a craniodental measure to describe sexual dimorphism in canids: Golden jackals (Canis aureus) and African wolves (Canis lupaster)
}

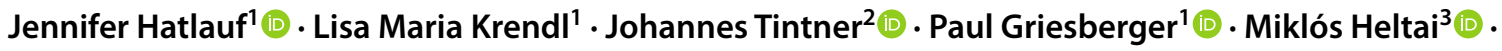 \\ Georgi Markov $^{4} \cdot$ Suvi Viranta $^{5}$ (i) $\cdot$ Klaus Hackländer $^{1,6}$
}

Received: 11 February 2021 / Accepted: 17 May 2021 / Published online: 18 June 2021

(c) The Author(s) 2021

\begin{abstract}
Sexual dimorphism is a widespread phenomenon among mammals, including carnivorans. While sexual dimorphism in golden jackals (Canis aureus) has been analysed in the past, in the related and apparently convergent canid, the African wolf (Canis lupaster), it is poorly studied and showed to be relatively small. Previously, sexual size dimorphism (SSD) research in these species was mostly based on skull and body measurements. In our study, we also included dental measurements, namely the diameter of the canine. We used 11 measured sections of 104 adult specimens, comprising 61 golden jackal and 43 African wolf skulls. Data analyses were carried out through logistic regression and conditional inference trees (CIT). To compare the results of SSD to other species, sexual dimorphism indices (SDI) were calculated. Golden jackals and African wolves show significant sexual size dimorphism, both in cranial and dental size. The logistic regression revealed that the mesiodistal diameter of the upper canine is most effective in discerning the sexes. The difference in the calculated SDI of the canine diameter between the sexes amounted to 8.71 in golden jackals and 14.11 in African wolves, respectively-with regional diversity. Thus, the canine diameter is an important measure to investigate SSD as well as an easy tool to apply in the field.
\end{abstract}

Keywords Canidae $\cdot$ Skull morphometrics $\cdot$ Sexual dimorphism index $\cdot$ Craniodental dimensions

\section{Introduction}

The golden jackal (Canis aureus Linnaeus, 1758) and the African wolf (Canis lupaster Hemprich and Ehrenberg, 1832) are medium-sized canid species living in monogamy (Jhala and Moehlman 2004). Despite the genetic distance (Gopalakrishnan et al. 2018), and probably as a result of

Handling Editor: Gabriele Sansalone.

Jennifer Hatlauf

jennifer.hatlauf@boku.ac.at

1 Department of Integrative Biology and Biodiversity Research, Institute of Wildlife Biology and Game Management, University of Natural Resources and Life Sciences, Vienna (BOKU), Gregor-Mendel Str. 33, 1180 Vienna, Austria

2 Department of Material Sciences and Process Engineering, Institute of Physics and Materials Science, University of Natural Resources and Life Sciences, Vienna (BOKU), Peter Jordan Str. 82, 1190 Vienna, Austria convergent evolution (Koepfli et al. 2015; Viranta et al. 2017), the two species show a phenotypic similarity, and therefore have previously been considered as one species (Jhala and Moehlman 2004; Rueness et al. 2011). Despite their similarity, the African wolf is shown to be a cryptic species more closely related to the grey wolf (Canis lupus) than to the golden jackal (Spassov 1989; Koepfli et al. 2015; Viranta et al. 2017). Consequently, the African wolf was

3 Department of Wildlife Biology, Faculty of Agricultural and Environmental Sciences, Institute for Conservation of Natural Resources, Szent István University, 1 Páter K. street, 2100 Gödöllő, Hungary

4 Bulgarian Academy of Sciences, Institute of Biodiversity and Ecosystem Research, 1 Tzar Osvoboditel, 1000 Sofia, Bulgaria

5 Department of Anatomy, Faculty of Medicine, University of Helsinki, PO Box 63, 00014 Helsinki, Finland

6 Deutsche Wildtier Stiftung (German Wildlife Foundation), Christoph-Probst-Weg 4, 20251 Hamburg, Germany 
firstly assessed for the IUCN Red List of threatened species as a separate species in 2019 , with a decreasing population trend (Hoffmann and Atickem 2019).

Sexual size dimorphism (SSD) is common among mammalian carnivores and is manifested in body size and corresponding measurements. SSD in canid craniodental dimensions, with males being usually larger than females, has been shown in several taxa including red foxes (Vulpes vulpes) (Szuma 2000, 2008; Jojić et al. 2017), coyotes (Canis latrans) (Kennedy et al. 2003) and grey wolves (Milenkovic et al. 2010). The degree of sexual dimorphism in red foxes varies geographically, reaching from $3 \%$ in Israel, up to $5-7 \%$ in Wales (Szuma 2008). SSD in coyotes ranges from 4 to $6 \%$, but no geographic variation in dimorphism was documented across Central and Eastern United States (Kennedy et al. 2003). Few studies have reported SSD in African wolves. For Egyptian specimen of African wolves, male and female dimensions appeared to be different (Osborn and Helmy 1980; Younes and Fouad 2016). The skulls of males are relatively wider, and females tended to have a shorter snout (Younes and Fouad 2016). Van Valkenburgh and Wayne (1994) found SSD in the mediolateral dimension of the upper canine in both the golden jackal and the African wolf, where the average difference was $4 \%$ (in a range of $0-13 \%$ ). However, most of their studied populations did not differ significantly in the canine diameter and skull length (Van Valkenburgh and Wayne 1994). In golden jackals, the overall dimorphism of skull size has been shown to be generally low and less pronounced compared to other canid species (Stoyanov 2012, 2020; Porobić et al. 2016; Markov et al. 2017; Raichev et al. 2017). Multivariate analysis of skull size and shape failed to identify differences between males and females (Stoyanov 2019).

Although dimorphism is highest in solitary carnivorous species (Law 2019), all canids show some degree of SSD (Bidau and Martinez 2016) — and the degree correlates well with the breeding system. Generally, canids with facultative monogamy and male provision have a decreased degree of the SSD, while multiple female systems show increased SSD. In both, the African wolf and the golden jackal, males and females live in monogamy and both sexes participate in bringing up the pups (Moehlman and Hayssen 2018), with the degree of the SSD being moderate. In the study of Gittleman and Van Valkenburgh (1997), the greatest degree of dimorphism in the craniodental features was found in the upper canines, which was also found to correlate with the breeding system. Furthermore, the role of the carnivore canines is more in display than actual fights (Plavcan and Ruff 2008). Usually, they are used in antagonistic male-male situations, which are more common in systems where males frequently compete for mates-therefore, not in golden jackals or African wolves. Moreover, because canids use olfaction in addition to visual cues in communication, the canines and their size may be of less significance for the interactions of canid males than in males of other carnivores (Gittleman and Van Valkenburgh 1997).

Because of previous unclear differentiation between sexes, we investigated cranial and dental variables of golden jackals and African wolves to test if these canids show SSD in specific measurements. We hypothesise that there is SSD in craniodental measurements (especially concerning the canine) in both species (therefore indicating convergence in aspects of their evolution) with males being larger than females.

\section{Materials and methods}

\section{Craniometry}

We aged all skulls according to tooth wear of the upper incisors and first upper molars (Harris 1978; Raychev et al. 1999; Roulichová and Anděra 2007). Age estimations obtained by this method were also supported by examination of the occlusion of cranial sutures (Harris 1978; Raychev et al. 1999) and fissures in canine teeth (Roulichová and Anděra 2007). In addition, we performed dental cementum analyses on non-museum specimens, wherever it was possible (Samweber et al. 2018; Krendl 2019).

For this study, we took measurements on 60 adult specimens and included 44 from Viranta et al. (2017). The combined dataset comprised 61 golden jackal (47 skulls from Europe and 14 from the Middle East and Asia) and 43 African wolf skulls (Table 1). The sample consisted of 38 females and 66 males. Measurements were taken with a calibrated digital sliding calliper (Mitutoyo Digital Calliper and Tera ${ }^{\circledR}$ Digital Calliper) to the nearest $0.01 \mathrm{~mm}$.

We chose 11 measurements based on previous studies (Table 2 and Fig. 1) - including five dorsal and four ventral skull measurements, as well as two mandible measurements.

Table 1 Sample sizes of female and male golden jackal (Canis aureus) and African wolf (Canis lupaster) skulls from different regions

\begin{tabular}{llcl}
\hline Species & Region or country & Sample size & Female/male \\
\hline Canis aureus & Western Europe & 7 & $2 / 5$ \\
Canis aureus & Hungary & 19 & $7 / 12$ \\
Canis aureus & Bulgaria & 21 & $5 / 16$ \\
Canis aureus & Middle East & 9 & $3 / 6$ \\
Canis aureus & Asia & 5 & $3 / 2$ \\
Canis lupaster & North Africa & 20 & $8 / 12$ \\
Canis lupaster & East Africa & 15 & $5 / 10$ \\
Canis lupaster & Central- and West- & 8 & $5 / 3$ \\
& Africa & & \\
\hline
\end{tabular}


Table 2 Listed measurements, which were included in the analyses are shown in Fig. 1

\begin{tabular}{|c|c|c|}
\hline Dorsal & Ventral & Mandible \\
\hline 1. dorsal total length (DTL) $)^{\mathrm{a}, \mathrm{b}}$ & 6. rostral breadth over canines $(\mathrm{RB})^{\mathrm{c}}$ & \multirow{5}{*}{$\begin{array}{l}\text { 10. mandibular length (infradentale to condylar process) } \\
(\mathrm{ML})^{\mathrm{a}, \mathrm{b}} \\
\text { 11. coronoid height of mandible }(\mathrm{MH})^{\mathrm{a}}\end{array}$} \\
\hline 2. zygomatic breadth $(\mathrm{ZB})^{*, a, b}$ & 7. condylobasal length $(\mathrm{CBL})^{\mathrm{a}, \mathrm{b}}$ & \\
\hline 3. postorbital breadth $(\mathrm{PB})^{\mathrm{a}, \mathrm{b}}$ & 8. palatal length $(\mathrm{PL})^{\mathrm{a}}$ & \\
\hline 4. ectorbital breadth $(\mathrm{EB})^{\mathrm{a}}$ & 9. mesiodistal diameter of upper canine tooth $(\mathrm{C})^{\mathrm{d}}$ & \\
\hline 5. interorbital breadth $(\mathrm{IB})^{\mathrm{a}, \mathrm{b}}$ & & \\
\hline
\end{tabular}

*Measured at maximum breadth

${ }^{\mathrm{a}}$ von den Driesch (1976), ${ }^{\mathrm{b}}$ Markov et al. (2017), ${ }^{\mathrm{c}}$ Krystufek and Tvrtkovic (1990), ${ }^{\mathrm{d}}$ Van Valkenburgh and Wayne (1994)
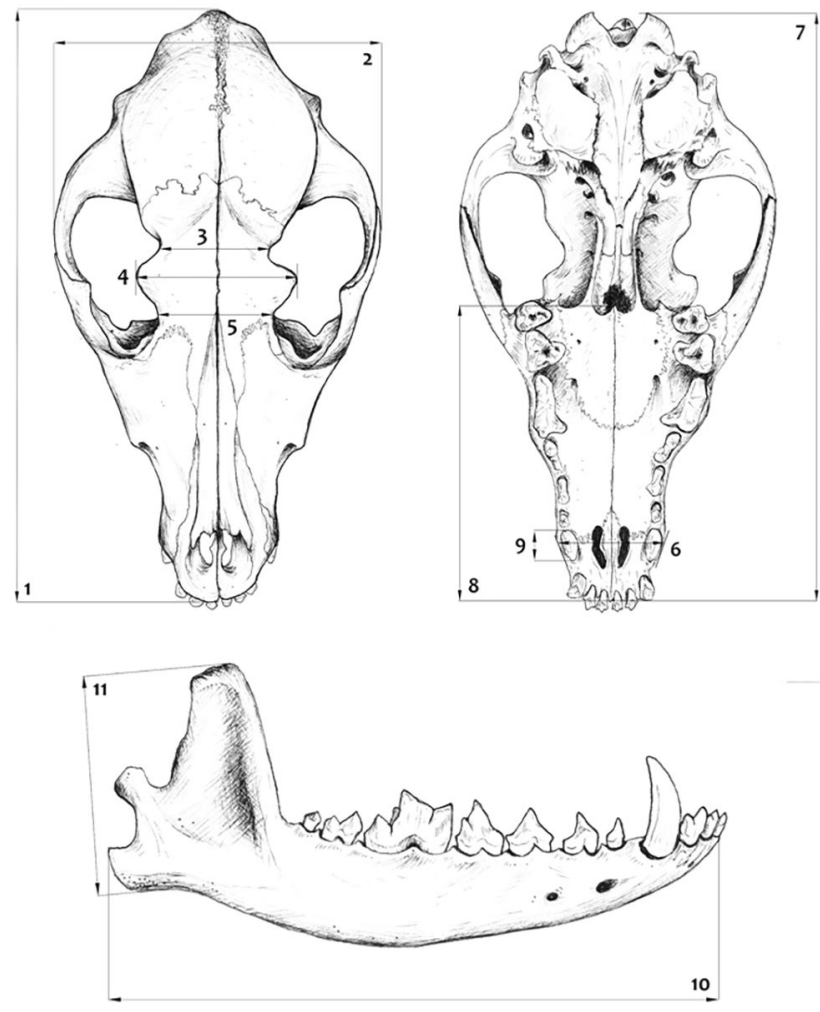

Fig. 1 Graphical representation of skull measurements taken on golden jackal and African wolf skulls (illustration by Jasmin Barl), listed and explained in Table 2

These were chosen to represent and describe the craniodental features of the skulls.

\section{Statistical analyses}

Basic statistical parameters to summarise all measurements for both species and different sexes were calculated with the help of R (R Core Team 2017) in RStudio Version 1.1.442 (RStudio Team 2016) and displayed with IBM ${ }^{\circledR}$ SPSS24 (boxplot in Online Resource 1 in

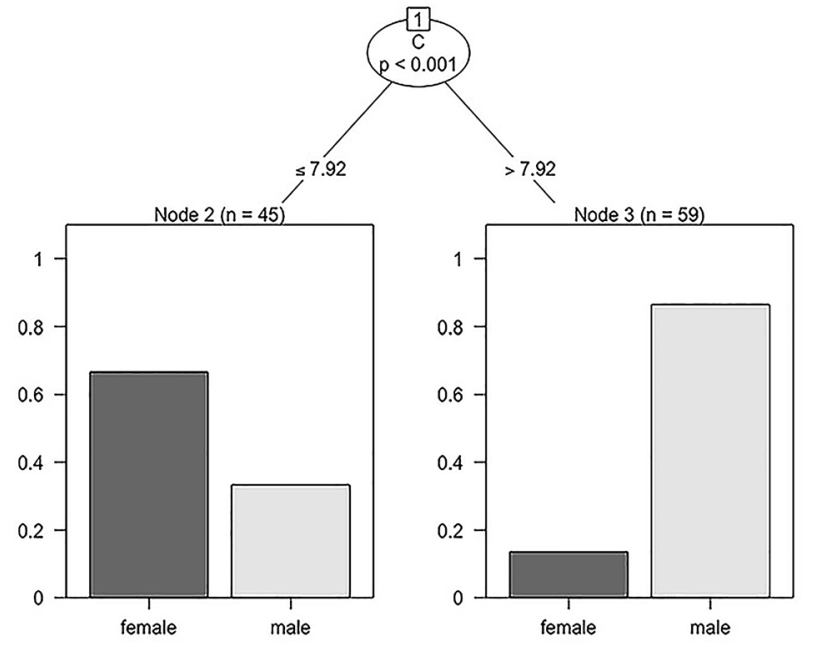

Fig. 2 Conditional inference tree (CIT) visualising the distinction of adult male (light grey) and female (dark grey) golden jackals and African wolves $(n=104)$. The graph displays $C$ as the most important factor $(p<0.001)$

Supplementary Information (SI) Fig. 1, 2). The detailed sample size, missing values, mean and median, standard deviation, and the minimum and maximum of each measured parameter were determined.

\section{Logistic regression and conditional inference trees}

To investigate the ranked relevance of the different morphological measures for SSD, a binary logistic regression was performed with IBM ${ }^{\circledR}$ SPSS 24 . We used a forward model selection routine, which ranks the different measures according to their effectiveness. The model was calibrated with a random test set size of $15 \%$ of the sample. A conditional inference tree (CIT) was constructed and a Welch test for the factor "sex" was performed using RStudio Version 1.1.442 (RStudio Team 2016). The CIT was performed and visualised employing the R package "party" ver. 1.3-1 (Hothorn et al. 2006). With the CIT, the importance of variables was evaluated, and critical thresholds for necessary measurements were obtained (Müller et al. 2009; Polo 
Aparisi et al. 2018). Skulls of shot specimens or road-killed golden jackals sometimes show damages or missing teeth; deformations can also occur during the boiling or drying process, preventing some of the skull measuring. As a result, full data series were not available in all cases and the sample size differed between the logistic regression $(n=81)$ and the CIT $(n=104)$.

\section{Sexual dimorphism index (SDI)}

The Welch test was applied for each species to test if the means for the calculation of the SSD ratios are significantly different. An advantage of calculating ratios is the information about the extent of SSD between different populations of the same species or among different species (Lovich and Gibbons 1992). A quantitative comparison of intraspecific and interspecific dimorphism (Lovich and Gibbons 1992) allows us to contrast the results with other research, which is why we included the sexual dimorphism index (SDI). According to previous studies on dimorphism in canids (Szuma 2008; Raichev et al. 2017), the SDI was calculated as follows: $S D I= \pm\left(\frac{M_{\mathrm{L}}}{M_{\mathrm{S}}}-1\right) \times 100\left[M_{\mathrm{L}}=\right.$ the larger value; $M_{\mathrm{S}}=$ the smaller value] (Smith 1999). Accordingly, we calculated the SDI for both species and consequently compared it to other canids' SDI.

\section{Results}

The basic descriptive statistics for the examined craniometrical measurements of all skulls for each sex and species show that male and female skulls display a broad range of values (Table 3, and in SI Fig. 1). In the African wolf sample, the male/female ( \pm Standard deviation, $S D)$ measurements vary from $135 / 133.2 \mathrm{~mm}$ to $194.96 / 170.7 \mathrm{~mm}$ (DTL, with the highest standard deviation of all measurements for the male specimen: $\pm 15.99 \mathrm{~mm}$ and $\pm 8.61 \mathrm{~mm}$ for females), $128 / 121.60 \mathrm{~mm}$ to $181.45 / 160.25 \mathrm{~mm}$ (CBL; with the second highest standard deviation of $\pm 15.43 \mathrm{~mm}$ for males and $8.73 \mathrm{~mm}$ for females), $34.6 / 36.70 \mathrm{~mm}$ to $50.2 / 45.80 \mathrm{~mm}(\mathrm{~EB} ; \mathrm{SD} \pm 4.05 / \pm 2.64 \mathrm{~mm})$, $22.3 / 24.50 \mathrm{~mm}$ to $35.53 / 30.80 \mathrm{~mm}$ (IB; $\mathrm{SD} \pm 3.08 / \pm 1.95 \mathrm{~mm}), 22.40 / 24.40 \mathrm{~mm}$ to $35.11 / 28.00 \mathrm{~mm}$ $(\mathrm{RB} ; \mathrm{SD} \pm 2.81 / \pm 1.16 \mathrm{~mm}), 64.8 / 66.80 \mathrm{~mm}$ to 94.62/81.94 mm (PL; SD $\pm 7.97 / \pm 4.04 \mathrm{~mm}), 98 / 97.1 \mathrm{~mm}$ to $141.23 / 123.52 \mathrm{~mm}(\mathrm{ML} ; \mathrm{SD} \pm 12.08 / \pm 7.16 \mathrm{~mm}$ ). The measurements of golden jackal male/female specimen varied from $140.60 / 135 \mathrm{~mm}$ to $173.34 / 169.24 \mathrm{~mm}$ $(\mathrm{DTL} ; \mathrm{SD} \pm 8.54 / \pm 11.06 \mathrm{~mm}), 129.1 / 131.0 \mathrm{~mm}$ to $166.39 / 159.27 \mathrm{~mm}(\mathrm{CBL} ; \mathrm{SD} \pm 9.35 / 8.28), 37.68 / 36.30 \mathrm{~mm}$ to $48.76 / 45.24 \mathrm{~mm}(\mathrm{~EB} ; \mathrm{SD} \pm 2.66 / 2.64), 22.90 / 23.70 \mathrm{~mm}$ to $29.29 / 29.14 \mathrm{~mm}$ (IB; $\mathrm{SD} \pm 1.73 / 1.68), 22.56 / 22.60 \mathrm{~mm}$ to $31.24 / 30.51 \mathrm{~mm}(\mathrm{RB} ; \mathrm{SD} \pm 1.44 / \pm 1.75), 68.10 / 68.80 \mathrm{~mm}$ to $84.78 / 80.21 \mathrm{~mm}(\mathrm{PL} ; \mathrm{SD} \pm 3.93 / 3.75), 99.10 / 101.90 \mathrm{~mm}$ to $133.51 / 126.16 \mathrm{~mm}(\mathrm{ML} ; \mathrm{SD} \pm 8.01 / 8.30)$.

\section{Sexual size dimorphism (SSD)}

The forward procedure of the logistic regression ranked the measure $C$ to be the most effective in describing SSD. As the second most important measure, zygomatic breadth (ZB) was selected. Nagelkerke's $R^{2}$ was calculated to $40.60 \%$. The classification resulted in $78.30 \%$ of correctly predicted values in the calibration set and $91.70 \%$ in the test set (results can be found in SI Tables 1-3 sample overview boxplot of measurement $C$ in SI Fig. 1).

The Welch test revealed significant differences in canine values between male and female skulls $(p<0.001$, $d f=77.80, \mathrm{MD}=0.86$ ).

The only, and most significant primary split in the CIT, for the whole dataset, was $C$. The overall CIT model showed that $78.94 \%$ of the females had a $C$ lower or equal to $7.92 \mathrm{~mm}$. Similarly, $77.27 \%$ (calculated on the basis of the CIT) of the males in the sample had a $C$ greater than $7.92 \mathrm{~mm}$ (Fig. 2).

\section{Sexual dimorphism index (SDI)}

The highest values of SSD were shown in the measurement of the mesiodistal diameter of upper canine tooth $(C)$ and the coronoid height of mandible in both species (Table 4). Golden jackals show a higher SDI in several measurements and a higher mean sexual dimorphism index (MDI-the grand mean of all intraspecific ratios of male over female values), whereas African wolves display a specifically high dimorphism only in $C$ (but high variation throughout the origin regions; see Table 5) and a low overall MDI (3.95, $\mathrm{SD} \pm 3.99)$.

The mean $C$ value of golden jackal adult females $(n=20)$ amounted to $7.81 \mathrm{~mm}$, and male golden jackals showed a higher mean value of $C$ amounting to $8.49 \mathrm{~mm}(n=39)$ $(d f=32.8, p<0.01)$ (Fig. 3). Therefore, males had an $8.71 \%$ greater canine diameter than females $(\mathrm{SDI}=8.71)$. Female African wolves showed a mean $C$ value of $7.37 \mathrm{~mm}(n=18)$ and males of $8.41 \mathrm{~mm}(\mathrm{n}=27)(d f=41.8, p<0.01)$, and thus, African wolf males had $14.11 \%$ greater canine diameter than females (SDI = 14.11) (Table 4; detailed regional discrimination of ratios is shown in Table 5). 
Table 3 Summarized data of all 11 craniometrical parameters for all golden jackal (Canis aureus) and African wolf (Canis lupaster) skulls $(n=104)$ for males (m) and females (f)

\begin{tabular}{|c|c|c|c|c|c|c|c|c|c|c|c|c|}
\hline & Species/sex & DTL & ZB & PB & EB & IB & RB & CBL & PL & C & ML & $\mathrm{MH}$ \\
\hline \multirow[t]{4}{*}{ Sample size } & C. lupaster $\mathrm{m}$ & 25 & 23 & 26 & 26 & 26 & 27 & 25 & 26 & 27 & 22 & 23 \\
\hline & C. aureus $\mathrm{m}$ & 36 & 33 & 35 & 37 & 37 & 37 & 36 & 36 & 39 & 36 & 36 \\
\hline & C. lupaster $\mathrm{f}$ & 18 & 17 & 17 & 17 & 17 & 18 & 18 & 18 & 18 & 18 & 18 \\
\hline & C. aureus $\mathrm{f}$ & 19 & 19 & 17 & 16 & 17 & 20 & 19 & 20 & 20 & 18 & 19 \\
\hline \multirow[t]{4}{*}{ Missing } & C. lupaster $\mathrm{m}$ & 2 & 4 & 1 & 1 & 1 & 0 & 2 & 1 & 0 & 5 & 4 \\
\hline & C. aureus $\mathrm{m}$ & 3 & 6 & 4 & 2 & 2 & 2 & 3 & 3 & 0 & 3 & 3 \\
\hline & C. lupaster $\mathrm{f}$ & 0 & 1 & 1 & 1 & 1 & 0 & 0 & 0 & 0 & 0 & 0 \\
\hline & C. aureus $\mathrm{f}$ & 1 & 1 & 3 & 4 & 3 & 0 & 1 & 0 & 0 & 2 & 1 \\
\hline \multirow[t]{4}{*}{ Mean } & C. lupaster $\mathrm{m}$ & 158.84 & 87.36 & 31.34 & 41.45 & 28.79 & 27.34 & 148.06 & 77.32 & 8.41 & 114.64 & 45.36 \\
\hline & C. aureus $\mathrm{m}$ & 163.13 & 89.79 & 28.25 & 43.18 & 26.41 & 29.48 & 153.82 & 78.02 & 8.49 & 120.98 & 48.60 \\
\hline & C. lupaster $\mathrm{f}$ & 152.52 & 84.73 & 31.73 & 41.34 & 28.47 & 26.18 & 141.48 & 75.29 & 7.37 & 110.27 & 42.73 \\
\hline & C. aureus $\mathrm{f}$ & 154.53 & 85.72 & 28.32 & 40.99 & 25.77 & 27.63 & 149.30 & 75.30 & 7.81 & 114.97 & 44.69 \\
\hline \multirow[t]{4}{*}{ Median } & C. lupaster $\mathrm{m}$ & 156.60 & 86.50 & 32.38 & 40.93 & 28.48 & 27.40 & 144.00 & 76.45 & 8.33 & 112.55 & 44.74 \\
\hline & C. aureus $\mathrm{m}$ & 164.67 & 90.07 & 28.30 & 42.74 & 26.50 & 29.51 & 155.77 & 78.93 & 8.54 & 122.67 & 48.99 \\
\hline & C. lupaster $\mathrm{f}$ & 150.44 & 84.85 & 31.76 & 41.59 & 28.30 & 26.40 & 141.75 & 74.50 & 7.31 & 109.31 & 42.62 \\
\hline & C. aureus $\mathrm{f}$ & 155.97 & 85.57 & 28.50 & 40.97 & 25.52 & 27.54 & 150.34 & 75.11 & 7.79 & 116.07 & 44.50 \\
\hline \multirow[t]{4}{*}{ SD } & C. lupaster $\mathrm{m}$ & 15.99 & 7.04 & 3.14 & 4.05 & 3.08 & 2.81 & 15.43 & 7.97 & 0.92 & 12.08 & 5.32 \\
\hline & C. aureus $\mathrm{m}$ & 8.54 & 3.17 & 2.55 & 2.66 & 1.73 & 1.44 & 9.35 & 3.93 & 0.55 & 8.01 & 2.55 \\
\hline & C. lupaster $\mathrm{f}$ & 8.61 & 4.20 & 2.46 & 2.64 & 1.95 & 1.16 & 8.73 & 4.04 & 0.72 & 7.16 & 3.18 \\
\hline & C. aureus $\mathrm{f}$ & 11.06 & 3.00 & 3.47 & 2.64 & 1.68 & 1.75 & 8.28 & 3.75 & 0.65 & 8.30 & 3.57 \\
\hline \multirow[t]{4}{*}{ Min } & C. lupaster $\mathrm{m}$ & 135.00 & 78.00 & 24.31 & 34.60 & 22.30 & 22.40 & 128.00 & 64.80 & 7.12 & 98.00 & 38.20 \\
\hline & C. aureus $\mathrm{m}$ & 140.60 & 77.45 & 23.53 & 37.68 & 22.90 & 22.56 & 129.10 & 68.10 & 7.10 & 99.10 & 37.74 \\
\hline & C. lupaster $\mathrm{f}$ & 133.20 & 75.12 & 27.40 & 36.70 & 24.50 & 24.40 & 121.60 & 66.80 & 6.20 & 97.10 & 38.20 \\
\hline & C. aureus $\mathrm{f}$ & 135.00 & 80.86 & 19.97 & 36.30 & 23.70 & 22.60 & 131.00 & 68.80 & 6.80 & 101.90 & 38.40 \\
\hline \multirow[t]{4}{*}{ Max } & C. lupaster $\mathrm{m}$ & 194.62 & 104.09 & 36.90 & 50.20 & 35.53 & 35.11 & 181.45 & 94.62 & 10.42 & 141.23 & 59.51 \\
\hline & C. aureus $\mathrm{m}$ & 173.34 & 95.80 & 34.90 & 48.76 & 29.29 & 31.24 & 166.39 & 84.78 & 9.63 & 133.51 & 51.88 \\
\hline & C. lupaster $\mathrm{f}$ & 170.60 & 89.80 & 35.80 & 45.80 & 30.80 & 28.00 & 160.25 & 81.94 & 9.40 & 123.52 & 49.10 \\
\hline & C. aureus $\mathrm{f}$ & 169.24 & 90.10 & 33.84 & 45.24 & 29.14 & 30.51 & 159.27 & 80.21 & 9.50 & 126.16 & 49.62 \\
\hline \multirow[t]{2}{*}{$p$ value } & C. lupaster & 0.104 & 0.149 & 0.653 & 0.919 & 0.673 & 0.065 & 0.084 & 0.276 & $<0.001$ & 0.165 & 0.058 \\
\hline & C. aureus & 0.006 & $<0.001$ & 0.937 & 0.010 & 0.205 & $<0.001$ & 0.073 & 0.014 & $<0.001$ & 0.016 & $<0.001$ \\
\hline
\end{tabular}

$D T L$ dorsal total length, $Z B$ zygomatic breadth, $P B$ postorbital breadth, $E B$ ectorbital breadth, $I B$ interorbital breadth, $R B$ rostral breadth over canines, $C B L$ condylobasal length, $P L$ palatal length, $C$ mesiodistal diameter of upper canine tooth, $M L$ mandibular length (infradentale to condylar process), $M H$ coronoid height of mandible; the statistical significance ( $p$ value; significance shown in bold) of the differences between the measurements of males and females of each species, calculated by the Welch test

Table 4 Sexual Dimorphism Index (SDI) for all measurements (description of measurements in Table 2) of both species, and the mean dimorphism index (MDI) ( \pm standard deviation-SD) as the grand mean of all intraspecific ratios of the male over female values

\begin{tabular}{|c|c|c|c|c|c|c|c|c|c|c|c|c|}
\hline Species & DTL & ZB & $\mathrm{PB}$ & $\mathrm{EB}$ & IB & $\mathrm{RB}$ & CBL & PL & $\mathrm{C}$ & ML & $\mathrm{MH}$ & MDI $( \pm S D)$ \\
\hline C. aureus & 5.57 & 4.75 & -0.25 & 5.34 & 2.48 & 6.70 & 3.03 & 3.61 & 8.71 & 5.23 & 8.75 & $4.90( \pm 2.66)$ \\
\hline C. lupaster & 4.14 & 3.10 & -1.23 & 0.27 & 1.12 & 4.43 & 4.65 & 2.70 & 14.11 & 3.96 & 6.15 & $3.95( \pm 3.99)$ \\
\hline
\end{tabular}

A negative sign is used when the female trait is larger

\section{Discussion}

Our study demonstrates that both the golden jackal and
African wolf specimens show significant differences between adult male and female craniodental dimensions, confirming our hypothesis, that there is SSD in both species. The best measurements (for all regions combined) to 
Table 5 Sexual dimorphism index (SDI) for all measurements (explanation in main Table 2) of both species with a more detailed discrimination in regions, and the mean dimorphism index (MDI) ( \pm Stand-

\begin{tabular}{llrrrrrrrrrrrr}
\hline Species & Region & DTL & ZB & PB & EB & IB & RB & CBL & PL & C & ML & MH & MDI \\
\hline C. aureus & Asia & 1.16 & 2.74 & 7.26 & 5.52 & -1.47 & 12.06 & -7.79 & -3.45 & 7.64 & -0.35 & 4.82 & 2.56 \\
& Near East & 7.38 & 12.97 & 0.98 & 16.69 & 9.43 & 9.69 & 0.62 & 0.14 & -3.59 & 9.25 & 19.98 & 7.59 \\
& Europe (summary) & 6.09 & 5.15 & -4.95 & 1.26 & -1.36 & 7.56 & 3.72 & 4.18 & 8.79 & 5.79 & 10.04 & 4.21 \\
C. lupaster & Eastern Africa & -0.01 & 1.56 & -0.89 & -2.30 & 0.62 & 0.42 & 0.62 & 0.05 & 7.94 & 1.98 & 5.59 & 1.42 \\
& Northern Africa & 8.84 & 6.91 & 0.74 & 4.48 & 7.45 & 8.32 & 8.73 & 6.01 & 12.66 & 6.72 & 10.81 & 7.42 \\
& Western/Central Africa & 3.56 & 3.44 & -0.51 & -0.64 & -0.20 & 6.26 & 4.71 & 4.76 & 22.02 & 4.61 & 2.19 & 4.56 \\
\hline
\end{tabular}

A negative sign is used when the female trait is larger

Fig. 3 Boxplot for the measurement $C$ of females and males in golden jackals (Canis aureus) and African wolves (Canis lupaster) (cf. SI Table 4) ard deviation, SD) as the grand mean of all intraspecific ratios of the male over female values

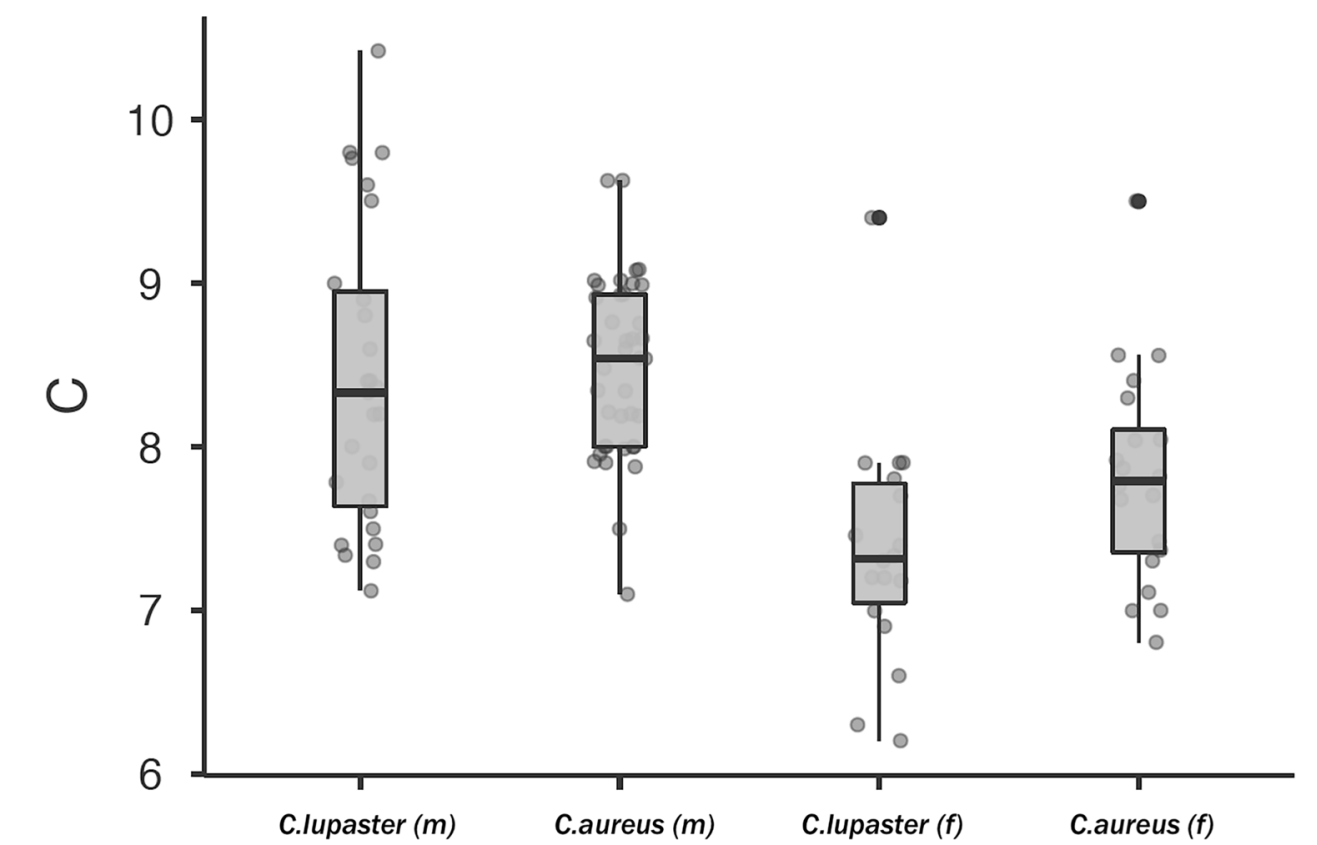

discriminate between sexes are the mesiodistal diameter of the upper canine tooth $(C)$ and the zygomatic breadth (ZB). Males show a larger canine diameter than females, both in golden jackals and in African wolves. With our findings, we can confirm the previously suggested sexual dimorphism in golden jackals (Stoyanov 2012, 2019; Porobić et al. 2016) and African wolves (Van Valkenburgh and Wayne 1994; Bertè 2017).

The SDI reveals that the body size dimorphism (in our study basically represented through the measure DTL- the skull length) is lower than specific measures like the canine size, suggesting an allometric change (most likely positive, but details of allometry still need to be assessed with further data). The SDI for $\mathrm{C}$ in our study was 8.71 for golden jackals and 14.11 for African wolves, being higher than in foxes (6, in Szuma 2008), and than previously found by Van Valkenburgh and Wayne (1994) for African wolves-where it ranged from 5 to 8 . SDI of the canine in golden jackals (from the Middle East, Pakistan, and India) ranged from 6 to 13 (Van Valkenburgh and Wayne 1994) positioning our results well in this range.

The difference within the African wolf samples (as shown in the SI Fig. 1 and SI Table 9) could partly be influenced by the presence of more than one species affiliation, that is not yet fully resolved (Krystufek and Tvrtkovic 1990; Viranta et al. 2017; Alvares et al. 2019), as suggested by the high variation within the sample. Indeed, recent studies based on geometric morphometric analyses suggest that the African wolf consists of two or three morphotypes that may present independent lineages, although this is not supported by genetic evidence (Machado and Teta 2020). The morphotypes may also differ in their ecology and social structure (Gaubert et al. 2012), what could influence the degree of sexual dimorphism.

Canids use their upper canines in prey capture and laceration, but they are less significant in mastication and the 
canids have weaker canines than other large carnivorous carnivorans (Van Valkenburgh and Ruff 1987; Christiansen and Adolfssen 2005). However, a few studies provide evidence that canid canines and SSD may be driven by ecological competition, and thus play an important role in feeding. Dayan et al. (1992) found character displacement in the canine diameters of five canid species in Israel and Egypt, suggesting that their size might be an adaptation to the preferred prey. The SSD was higher in the canine diameterwith as high as $12 \%$ in golden jackals from Israel-than in skull length or carnassial length in all species of their study (Dayan et al. 1992). Similarly, in our study, the skull length dimorphism of golden jackals and African wolves was relatively small, represented through the SDI of 5.56 and 4.14, respectively. While the degree of the canine SSD might show intraspecific variation in response to ecological competition within the guild, studies have found no evidence for correlation of the degree of SSD and intraguild competition in canids (Kennedy et al. 2003; Meiri et al. 2005). This indicates that the canine size, not the body size, may accommodate resource partitioning. While resource partitioning might not be a main mechanism causing sexual dimorphism (Kennedy et al. 2003), still, results from golden jackal stomach analyses showed nutritional differences between the sexes. Compared with males, females consumed $9.8 \%$ more plants (Lanszki et al. 2018), supporting the idea that this mechanism as additional driving force for sexual dimorphism.

Dimorphism in the canines has furthermore been associated with sexual selection (e.g., Randau et al. 2013). However, in the monogamous species, such as the golden jackal and African wolf, it is expected to be very low (Gittleman and Van Valkenburgh 1997). Our knowledge on the breeding ecology of these canids is insufficient, as there may even be geographic variation in the degree of monogamy, affecting the degree of dimorphism. This could explain the differences we found in the SDI for $\mathrm{C}$ between golden jackal and African wolf of different regions.

In an extensive study covering red fox populations throughout the Holarctic, Szuma (2008) found interpopulation variation in sexual dimorphism for all the tooth measurements (this largescale assessment remains to be done for golden jackals and African wolf). The largest geographic variation in the degree of SSD in foxes was found in the $\mathrm{m} 3$, a rudimentary molar that may not develop at all. The second largest geographic variation was found in the lower canine followed by the upper canine (as well shown in our study). This observed variation of the canines between populations has been explained by the simpler morphology (as compared to the rest of the dentition) and small size (Szuma 2000). Furthermore, the role of hormones in canine development and the variation in sexual dimorphism has also been speculated about (Lorber et al. 1979), although the role of sex hormones in dental development is not clear (e.g.,
Guatelli-Steinberg et al. 2008). As a likely result, in general the canine may be a good indicator of selection caused by competition-a result that yet needs to be assessed for these canids.

In conclusion, our study provides additional data that the robustness of the upper canine may be one of the most dimorphic dental (and cranial) character in canid populations. Furthermore, the implications of our study are twofold: the result of the CIT presents an interesting threshold-only one measure (the upper canine) - that can be very useful from a field research perspective. The obtained values are easy to apply for a quick first assessment of sex in both species. Second, the arrival of expanding species (as new competitors) may cause changes in dimorphism of already present species. Kauhala and Viranta (2011) showed decreased dimorphism in the Finnish red fox after the arrival of the raccoon dog, affecting mainly the carnassial grinding area. Hence, comparative studies on canids that will be sharing their habitats with another competitor in Europe in the near future-namely the golden jackal, which is rapidly expanding its range into new areas-will be of importance and scientific interest to observe potential changes in dimorphism within the carnivore guilds.

Supplementary Information The online version contains supplementary material available at https://doi.org/10.1007/s42991-021-00133-2.

Acknowledgements We thank the Natural History Museum Vienna, especially Frank Zachos, and the National Museum of Natural History in Sofia Bulgaria, specifically Nikolai Spassov, the Gemencz State Forestry Company, Hungary, and private collectors, who provided some of the skulls. Furthermore, we thank Stoyan Stoyanov for support in the ageing process, Jasmin Barl for the illustrations, and Laurent Schley, Robert Krickl and two anonymous reviewers for improving the Manuscript.

Author contributions JH, LK, and SV wrote the manuscript; JH, LK, PG, and JT analysed and visualised the data. KH, PG, and JT suggested the study design. $\mathrm{MH}$ and $\mathrm{MG}$ provided study material and all authors revised the manuscript.

Funding Open access funding provided by University of Natural Resources and Life Sciences Vienna (BOKU). This study was partially funded by OEAD and OMAA (Nr. 940̈u6). JH is a recipient of the DOC Fellowship of the Austrian Academy of Sciences at the Institute of Wildlife Biology and Game Management, University of Natural Resources and Life Sciences, Vienna (BOKU). LK was supported by the KUWI fund of the University of Natural Resources and Life Sciences, Vienna (BOKU). The publication is supported by the EFOP-3.6.3-VEKOP-16-2017-00008 project (HM). Open access funding provided by the University of Natural Resources and Life Sciences, Vienna (BOKU).

\section{Declarations}

Conflict of interest The authors declare that they have no conflict of interest. 
Ethics approval No animals were killed for the purpose of this study. All samples were obtained from individuals that were legally hunted or that died through accidental vehicle collision or natural cause.

Availability of data The analysed data are stored at the University of Natural Resources and Life Sciences, Vienna and provided upon request (jennifer.hatlauf@boku.ac.at).

Open Access This article is licensed under a Creative Commons Attribution 4.0 International License, which permits use, sharing, adaptation, distribution and reproduction in any medium or format, as long as you give appropriate credit to the original author(s) and the source, provide a link to the Creative Commons licence, and indicate if changes were made. The images or other third party material in this article are included in the article's Creative Commons licence, unless indicated otherwise in a credit line to the material. If material is not included in the article's Creative Commons licence and your intended use is not permitted by statutory regulation or exceeds the permitted use, you will need to obtain permission directly from the copyright holder. To view a copy of this licence, visit http://creativecommons.org/licenses/by/4.0/.

\section{References}

Alvares F, Sillero-Zubiri C, Jhala YV, Viranta S, Koepfli KP, Godinho R, Krofel M, Bogdanowicz W, Hatlauf J, Campbell L, Werhahn G, Senn H, Kitchener A (2019) Old World Canis spp. with taxonomic ambiguity: Workshop conclusions and recommendations. Workshop Conclusions and Recommendations. CIBIO, Vairão, Portugal, May 2019. Vairão, pp 1-8

Bertè DF (2017) Remarks on the skull morphology of Canis lupaster Hemprich and Herenberg, 1832 from the collection of the Natural History Museum "G. Doria” of Genoa, Italy. Nat History Sci 4(1):19-29. https://doi.org/10.4081/nhs.2017.318

Bidau CJ, Martinez PA (2016) Sexual size dimorphism and Rensch's rule in Canidae. Biol J Lin Soc 119(4):816-830

Christiansen P, Adolfssen JS (2005) Bite forces, canine strength and skull allometry in carnivores (Mammalia, Carnivora). J Zool 266(2):133-151

Dayan T, Simberloff D, Tchernov E, Yom-Tov Y (1992) Canine carnassials: character displacement in the wolves, jackals and foxes of Israel. Biol J Linnean Soc 45(4):315-331. https://doi.org/10. 1111/j.1095-8312.1992.tb00647.x

Gaubert P, Bloch C, Benyacoub S, Abdelhamid A, Pagani P, Djagoun CAMS, Couloux A, Dufour S (2012) Reviving the african wolf Canis lupus lupaster in north and west africa: a mitochondrial lineage ranging more than 6,000 km wide. PLoS ONE 7(8):e42740. https://doi.org/10.1371/journal.pone.0042740

Gittleman JL, Valkenburgh BVaN (1997) Sexual dimorphism in the canines and skulls of carnivores : effects of size, phylogeny, and behavioural ecology. J Zool 242(1):97-117. https://doi.org/10. 1111/j.1469-7998.1997.tb02932.x

Gopalakrishnan S, Sinding MHS, Ramos-Madrigal J, Niemann J, Samaniego Castruita JA, Vieira FG, Carøe C, de Montero MM, Kuderna L, Serres A, González-Basallote VM, Liu YH, Wang GD, Marques-Bonet T, Mirarab S, Fernandes C, Gaubert P, Koepfli KP, Budd J, Rueness EK, Heide-Jørgensen MP, Petersen B, Sicheritz-Ponten T, Bachmann L, Wiig Ø, Hansen AJ, Gilbert MTP (2018) Interspecific gene flow shaped the evolution of the Genus Canis. Curr Biol 28(21):3441-3449. https://doi.org/10. 1016/j.cub.2018.08.041

Guatelli-Steinberg D, Sciulli PW, Betsinger TK (2008) Dental crown size and sex hormone concentrations: another look at the development of sexual dimorphism. Am J Phys Anthropol 137(3):324-333. https://doi.org/10.1002/ajpa.20878

Harris S (1978) Age determination in the Red fox (Vulpes vulpes) - an evaluation of technique efficiency as applied to a sample of suburban foxes. J Zool 184:91-117. https://doi.org/10.1111/j.14697998.1978.tb03268.x

Hoffmann M, Atickem A (2019) Canis lupaster, African Wolf. The IUCN Red List of Threatened Species 2019

Hothorn T, Hornik K, Zeileis A (2006) Unbiased recursive partitioning: a conditional inference framework. J Comput Graphic Stat 15(3):651-674

Jhala Y, Moehlman P (2004) Golden jackal. In: Sillero-Zubiri C, Hoffmann M, Macdonald DW (eds), Canids: Foxes, Wolves, Jackals and Dogs. IUCN/SSC Canid Specialist Group, pp 156-161

Jojić V, Porobić J, Ćirović D (2017) Cranial variability of the Serbian red fox. Zool Anz 267:41-48. https://doi.org/10.1016/j.jcz.2017. 02.001

Kauhala K, Viranta S (2011) Increased carnivory in Finnish red fox females - Adaptation to a new competitor? Annales Zoologici Fennici 48(1):17-28. https://doi.org/10.5735/086.048.0102

Kennedy ML, Mech SG, Tran B, Grubaugh JW, Lance RF (2003) An assessment of geographic variation in sexual size dimorphism in the coyote (Canis latrans). Mammalia 67(3):411-417. https://doi. org/10.1515/mamm.2003.67.3.411

Koepfli KP, Pollinger J, Godinho R, Robinson J, Lea A, Hendricks S, Schweizer RM, Thalmann O, Silva P, Fan Z, Yurchenko AA, Dobrynin P, Makunin A, Cahill JA, Shapiro B, Alvares F, Brito JC, Geffen E, Leonard JA, Helgen KM, Johnson WE, O'Brien SJ, Van VB, Wayne RK (2015) Genome-wide Evidence Reveals that African and Eurasian Golden Jackals Are Distinct Species. Curr Biol 25(16):2158-2165

Krendl L (2019) Skull morphology of golden jackals (Canis aureus): sexual dimorphism and cranial variability. University of Natural Resources and Life Sciences, BOKU, Vienna, p 64

Krystufek B, Tvrtkovic N (1990) Variability and identity of the jackals (Canis aureus) of Dalmatia. Annalen Des Naturhistorischen Museums in Wien, Serie B 91:7-25

Lanszki J, Hayward MW, Nagyapáti N (2018) Feeding responses of the golden jackal after reduction of anthropogenic food subsidies. PLoS ONE 13(12):e0208727. https://doi.org/10.1371/journ al.pone. 0208727

Law CJ (2019) Solitary meat-eaters: solitary, carnivorous carnivorans exhibit the highest degree of sexual size dimorphism. Sci Rep 9(1):1-10. https://doi.org/10.1038/s41598-019-51943-x

Lorber M, Alvo G, Zontine WJ (1979) Sexual dimorphism of canine teeth of small dogs. Arch Oral Biol 24(8):585-589

Lovich J, Gibbons JW (1992) A review of techniques for quantifying sexual size dimorphism. Growth Dev Ageing 56:269-281

Machado FA, Teta P (2020) Morphometric analysis of skull shape reveals unprecedented diversity of African Canidae. J Mammal 20(10):1-12. https://doi.org/10.1093/jmammal/gyz214

Markov G, Kocheva M, Gospodinova M (2017) Patterns of sexual dimorphism and phenetic variety among the populations of the golden jackal (Canis aureus) in Bulgaria: insights from craniometric data. Balkan J Wildl Res 4(1):29-42. https://doi.org/10. 15679/bjwr.v4i1.49

Meiri S, Dayan T, Simberloff D (2005) Variability and sexual Size Dimorphism in Carnivores: Testing the Niche Variation Hypothesis. Ecology 86(6):1432-1440

Milenkovic M, Jojic V, Blagojevic J, Tatovic S, Vujosevic M (2010) Skull variation in Dinaric-Balkan and Carpathian gray wolf populations revealed by geometric morphometric approaches Skull variation in Dinaric-Balkan and Carpathian gray wolf populations revealed by geometric morphometric approaches. J Mammal 91(2):376-386. https://doi.org/10.1644/09-MAMM-A-265.1.Key 
Moehlman PD, Hayssen V (2018) Canis aureus (Carnivore: Canidae). Mamm Species 50(957):14-25. https://doi.org/10.1093/mspecies/ sey002

Müller D, Schröder B, Müller J (2009) Modelling habitat selection of the cryptic Hazel Grouse Bonasa bonasia in a montane forest. J Ornithol 150(4):717-732. https://doi.org/10.1007/ s10336-009-0390-6

Osborn DJ, Helmy I (1980) The contemporary land mammals of Egypt (including Sinai), volume Fieldiana. Field Museum of Natural History, Chicago. https://doi.org/10.5962/bhl.title.2801

Plavcan JM, Ruff CB (2008) Canine size, shape, and bending strength in primates and carnivores. Am J Phys Anthropol 136(1):65-84

Polo Aparisi M, Schöll EM, Hille SM (2018) Alpine Marsh Tits Poecile palustris palustris exhibit no clear sexual dimorphism other than in wing length. Ringing Migration 33(1):36-40. https://doi.org/ 10.1080/03078698.2018.1528715

Porobić J, Ćirović D, Jojić V (2016) Cranial variability of the Serbian golden jackal: geographic variation, sexual dimorphism and allometry. Zoologischer Anzeiger A Journal of Comparative Zoology 261(April):38-47. https://doi.org/10.1016/j.jcz.2016.03.004

R Core Team R: A Language and Environment for Statistical Computing. R Foundation for Statistical Computing (2017). Vienna. https://www.r-project.org. Accessed 1 Feb 2018

Raichev E, Peeva S, Masuda R, Kaneko Y, Tsunoda H, Georgiev D, Georgiev D (2017) Sexual dimorphism in body parameters of the golden jackal Canis aureus L., 1758 (Carnivora, Canidae) in the Sarnena Sredna Gora mountain and Tracian plain (Bulgaria). Trakia J Sci 15(2):135-140. https://doi.org/10.15547/tjs.2017.02.006

Randau M, Carbone C, Turvey ST (2013) Canine evolution in sabretoothed carnivores: natural selection or sexual selection? PLoS ONE 8(8):1-5. https://doi.org/10.1371/journal.pone.00728 68

Raychev E, Dimitrov R, Dimova T (1999) How to Determine the Age of the Golden Jackal Canis aureus by Cutting-teeth Attrition and Ossification of the Basal Cranial Synchrondroses. Bulgarian J Agr Sci 5:807-810

Roulichová J, Anděra M (2007) Age determination in the Red Fox (Vulpes vulpes): a comparative study. Lynx (praha) 38:55-71

RStudio Team RStudio: Integrated Development for R (2016). Boston. http://www.rstudio.com. Accessed 1 Feb 2018

Rueness EK, Asmyhr MG, Sillero-Zubiri C, Macdonald DW, Bekele A, Atickem A, Stenseth NC (2011) The Cryptic African Wolf: Canis aureus lupaster is not a golden jackal and is not endemic to Egypt. PLoS ONE 6(1):e16385. https://doi.org/10.1371/journ al.pone. 0016385
Samweber I, Griesberger P, Heltai M, Szabó L, Hackländer K, Hatlauf J (2018) Assessment of methods for age determination based on teeth and skull of the golden jackal. In: Proceedings of the 2nd International Jackal Symposium, Hellenic Zoological Archives. Marathon Bay, Attiki Province, pp 137-138

Smith RJ (1999) Statistics of sexual size dimorphism. J Hum Evol 36:423-458. https://doi.org/10.1006/jhev.1998.0281

Spassov N (1989) The position of jackals in the Canis genus and lifehistory of the golden jackal (Canis aureus L.) in Bulgaria and on the balkans. Historia Naturalis Bulgarica 1(December):44-55

Stoyanov S (2012) Craniometric Differentiation of Golden Jackals (Canis aureus L., 1758) in Bulgaria. In: International Symposium on Hunting "Modern Aspects of Sustainable Management of Game Population.” Zemun-Belgrade, pp 39-47

Stoyanov S (2019) Cranial variability and sexual dimorphism of golden jackal in Bulgaria. For Ideas 25(2):425-442

Stoyanov S (2020) Cranial variability and differentiation among golden jackals (Canis aureus) in Europe, Asia minor and Africa. ZooKeys 917:141-164. https://doi.org/10.3897/zookeys.917.39449

Szuma E (2000) Variation and correlation patterns in the dentition of the red fox from Poland. Ann Zool Fenn 37:113-127

Szuma E (2008) Geography of sexual dimorphism in the tooth size of the red fox Vulpes vulpes (Mammalia, Carnivora). J Zool Syst Evol Res 46(1):73-81. https://doi.org/10.1111/j.1439-0469.2007. 00418.x

Van VB, Ruff CB (1987) Canine tooth strength and killing behaviour in large carnivores. J Zool 212(3):379-397

Van VB, Wayne RK (1994) Shape divergence associated with size convergence in sympatric East African jackals. Ecology 75(6):15671581. https://doi.org/10.2307/1939618

Viranta S, Atickem A, Werdelin L, Stenseth NC (2017) Rediscovering a forgotten canid species. BMC Zoology 2(1):6. https://doi.org/ 10.1186/s40850-017-0015-0

von den Driesch A (1976) A guide to the measurement of animal bones from archaelogical sites. Peabody Museum of Archaeology and Ethnology, Harvard University, Cambridge, p 136

Younes MI, Fouad FF (2016) Cranial allometry, sexual dimorphism and age structure in sample of the Egyptian Wolf Canis anthus Lupaster. Al-Azhar Bull Sci 27(1):1-8

Publisher's Note Springer Nature remains neutral with regard to jurisdictional claims in published maps and institutional affiliations. 